Article

\title{
Immobilization of Saccharomyces cerevisiae on Apple Pieces to Produce Cider
}

\author{
Clelia Altieri ${ }^{\dagger}$, Daniela Campaniello ${ }^{\dagger}$, Barbara Speranza, Milena Sinigaglia,

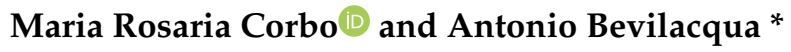 \\ Department of the Science of Agriculture, Food and Environment, University of Foggia, 71122 Foggia, Italy \\ * Correspondence: antonio.bevilacqua@unifg.it; Tel.: +39-0881-589231 \\ + These authors contributed equally to this work.
}

Received: 17 June 2019; Accepted: 7 August 2019; Published: 9 August 2019

\begin{abstract}
Three yeasts (Saccharomyces cerevisiae var. boulardii, a commercial probiotic yeast; S. cerevisiae W13, a wild yeast able to remove ochratoxin A; and S. cerevisiae 17, a wild yeast with promising probiotic traits) were screened for their ability to adhere on apple pieces as a function of different contact times (15-30 min). Then, apple pieces were stored at $4{ }^{\circ} \mathrm{C}$ for 15 days, and the viable count of yeasts was periodically assessed. Yeasts were able to adhere on apple pieces after $15 \mathrm{~min}(7 \mathrm{log} \mathrm{cfu} / \mathrm{g}$ ) and retained their viability throughout the refrigerated storage. In a second step, apple pieces with $S$. cerevisiae W13 were used to produce cider on a small scale. The variables under investigation were (a) the recycling of pieces up to 10 times and (b) the preliminary storage of pieces at $4{ }^{\circ} \mathrm{C}$ before use. Pieces used immediately after yeast immobilization could be successfully used again 10 times and gained a fermentation performance (in terms of yeast amount in cider and ethanol after $24 \mathrm{~h}$ ) similar to that achieved by free cells. In addition, the preliminary storage of pieces at $4{ }^{\circ} \mathrm{C} \operatorname{did}$ not affect their performances as reusable starter carriers.
\end{abstract}

Keywords: functional starter cultures; cell immobilization; Saccharomyces cerevisiae; reusable starter; functional cider

\section{Introduction}

Cell immobilization is the physical confinement or localization of intact cells to a certain region of space with the preservation of some desired catalytic activity [1].

Immobilization can be performed by (i) attachment/adsorption on solid carrier surfaces as a result of electrostatic forces and covalent binding between the cell membrane and the carrier, (ii) cross-linking by flocculation (natural) or with artificially induced cross-linking agents, and (iii) entrapment within a porous matrix by cell penetration until movement is interrupted by the presence of other cells as well as the formation of porous materials in situ into a cell culture [2].

Inorganic materials (zeolite, clay, anthracite, porous glass, activated charcoal, and ceramics) and organic polymers (acrylamide, polyurethane, polyvinyl, resins, alginate, carrageenan, agar, and agarose) can be used as carriers; however, the most interesting are polymers of natural origin (alginate and carrageenan), because they are friendly to the environment and have a low cost [3].

A new trend toward immobilization is the design of so-called "food-like systems", i.e., foods used as carriers for probiotics or starter cultures [3]. Corn starch gel, casein, gluten pellets, potatoes, wheat grains, and fruit pieces (e.g., apple and pear, guava, sugar cane, grape skin, and figs) have been studied and used for this purpose. Fruit pieces, mainly apple pieces, with yeasts have been proposed as reusable carriers for wine or probiotic fermented milk by a wide variety of authors, because they are abundant, easy to handle, and are generally accepted by consumers $[1,4,5]$. 
Saccharomyces cerevisiae is the traditional species for wine fermentation: it is also an interesting reservoir of probiotic and/or functional strains [6]. It includes the well-known probiotic strain Saccharomyces cerevisiae var. boulardii. This strain exerts several probiotic activities, such as the prevention and treatment of infectious enteritis and Clostridium difficile-associated enterocolopathies and the prevention of diarrhea: it also plays a significant role in alleviating the symptoms of necrotizing enterocolitis and exerts beneficial effects on Crohn's disease and ulcerative colitis [7-10]. Nevertheless, $S$. boulardii possesses good technological performance [3] and can be labeled as a functional starter culture, that is, "a starter culture with an added function, mainly health-oriented or quality-oriented" [11]. The use of yeasts with functional and/or probiotic traits is an increasing trend, and promising strains have been isolated in the past from a wide variety of matrices [6].

Petruzzi et al. [12,13] isolated some strains of S. cerevisiae with functional traits: they were able to remove ochratoxin A from the medium while performing fermentation.

Despite holding a smaller position on a global scale, cider production is common throughout Europe and has also spread to other western markets (North America, Australia) [14]. This beverage is experiencing an increasing interest because of its contents of phenols and bioactive compounds [15]. Several authors have studied different combinations of starter cultures for cider; however, few data are available on the use of immobilized yeasts for cider production.

Therefore, the main goal of this paper was to design apple pieces as functional carriers to produce cider. The secondary goal of this research was to study the effects of several factors, such as the time required for yeast attachment on the surface and the possibility of reusing carriers and using preliminarily stored carriers.

\section{Materials and Methods}

\subsection{Yeasts}

The yeasts used were the following:

- S. cerevisiae W13, isolated from Uva di Troia (Laboratory of Predictive Microbiology, Department of the Science of Agriculture, Food, and Environment (SAFE), University of Foggia, Foggia, Italy) and able to remove ochratoxin A [12];

- S. cerevisiae strain 17, isolated from Altamura bread DPA (Denomination of Protected Origin) sourdough (collection of the Laboratory of Predictive Microbiology) [16];

- S. cerevisiae var. boulardii ATCC MYA-796 (American Type Culture Collection).

Yeasts were maintained at $4{ }^{\circ} \mathrm{C}$ on yeast-peptone-glucose (YPG) slants (yeast extract, $10 \mathrm{~g} / \mathrm{L}$; bacteriological peptone, $10 \mathrm{~g} / \mathrm{L}$; glucose, $20 \mathrm{~g} / \mathrm{L}$; agar, $15 \mathrm{~g} / \mathrm{L}$ ). All ingredients were purchased from Oxoid (Milan, Italy).

\subsection{Immobilization on Apple Pieces}

Yeasts were grown in YPG broth $\left(30^{\circ} \mathrm{C}\right.$ for $\left.24 \mathrm{~h}\right)$, and the cells were harvested by centrifugation $(1200 \times g$ for $10 \mathrm{~min})$. Then, yeasts were immobilized on apple pieces using the protocol of Kopsahelis et al. [17], which was modified as follows.

First, apple pieces (Granny Smith variety, $2 \mathrm{~cm}$ and $4.5 \mathrm{~g}$ ) were dipped into an antibrowning solution $(0.2 \%$ citrate $+0.1 \%$ ascorbate solution). Then, pieces were dipped in yeast suspension (20-30 pieces in $250 \mathrm{~mL}$; yeasts $10^{7} \mathrm{cfu} / \mathrm{mL}$ ) for 15, 20, 25, and $30 \mathrm{~min}$. After the dipping, the pieces were removed from the solution and stored in sterile containers at $4{ }^{\circ} \mathrm{C}$ for 12 days. They were periodically analyzed to assess the viable count of yeasts. 15-20 g of apple pieces were diluted into a sterile saline solution $(0.9 \% \mathrm{NaCl})$ to obtain a 10 -fold dilution and homogenized through a laboratory blender. Then, the homogenates were serially diluted, and the viable count was evaluated through spread-plating on YPG agar $\left(25^{\circ} \mathrm{C}\right.$ for $\left.48-72 \mathrm{~h}\right)$. 


\subsection{Fermentation of Apple Juice}

For the second step, the experiments were performed with S. cerevisiae W13 loaded on apple pieces through a 15-min dipping.

Two different experiments were performed:

(1) Experiment (A). Yeast was immobilized on apple pieces, and the carriers were immediately used for apple juice fermentation;

(2) Experiment (B). Yeast was immobilized on apple pieces and then stored at $4{ }^{\circ} \mathrm{C}$ for 7 days. After the storage, the pieces were used for juice fermentation.

The experiments were done in commercial apple juice (soluble solids, $11^{\circ} \mathrm{Bx}$; sugars, $10.5 \%$; $\mathrm{pH}, 3.7$ ). The juice was analyzed to check for a lack of spoilers (aerobic bacteria on plate count agar, incubated at $30{ }^{\circ} \mathrm{C}$ for $24-48 \mathrm{~h}$; molds on potato dextrose agar, incubated at $25^{\circ} \mathrm{C}$ for $5-7$ days; yeasts on YPG agar; lactic acid bacteria on MRS agar (de Man Rogosa Sherman), incubated at $30{ }^{\circ} \mathrm{C}$ for $72 \mathrm{~h}$ under anaerobiosis).

Apple pieces ( 4 pieces in $100 \mathrm{~mL}$ ) were added to juice and incubated at $25{ }^{\circ} \mathrm{C}$. After $24 \mathrm{~h}$, the juice was filtered, and the pieces were used to start a new fermentation: this procedure was repeated 10 times for experiment $\mathrm{A}$ and 6 times for experiment $\mathrm{B}$.

Fermented apple juice and apple pieces were analyzed for an evaluation of yeast viability on YPG agar.

Control samples were prepared by inoculating apple juice with free cells $(7 \log \mathrm{cfu} / \mathrm{mL})$.

The ethanol $(\mathrm{g} / \mathrm{L})$ produced by yeasts after a 24-h fermentation was determined through a commercial enzymatic kit (Megazyme, Dublin, Ireland).

\subsection{Sensory Analyses}

Sensory scores were assessed after the fermentation by a panel composed of 10 untrained panelists (students and researchers of the Department of the Science of Agriculture, Food, and Environment (SAFE), University of Foggia). The samples were coded by a letter and were presented individually to each panelist in plastic cups covered with a lid in a random order. Using a scale ranging from 0 to 5 (where $0=$ very poor and $5=$ excellent), the sensorial overall quality of cider was determined. Panelists were asked to base their decision on evaluations of color and odor: therefore, sample overall quality had to be considered the average of the two sensory attributes.

\subsection{Statistical Analyses}

The experiments were performed on two independent batches and were repeated twice for each batch. The results of the first step were analyzed through a two-way analysis of variance and Tukey's test as a post hoc comparison test $(p<0.05)$. The contact time and the duration of the storage were used as categorical predictors, while the viability of yeasts was the dependent variable.

The results of the second step (viability of S. cerevisiae W13 on apple pieces and in cider, ethanol produced after 24-h fermentation) were analyzed through a one-way ANOVA $(p<0.05)$.

The results of sensory scores were analyzed through the nonparametric test of Friedman $(p<0.05)$. The statistical analyses were made through the software Statistica for Windows, ver. 12.0 (Statsoft, Tulsa, OK, USA).

\section{Results}

\subsection{Immobilization of Yeasts on Apple Pieces}

The goal of the first step (immobilization of yeasts on apple pieces) was to assess if the strains could be loaded on apple pieces by answering two questions: (a) "Is the duration of the piece-dipping in yeast solution significant?" In addition, (b) "What is the viability of yeasts on apple pieces during 
refrigerated storage?" Table 1 shows the standardized effects of contact time and storage, as well as their interaction. Contact time was not significant, as $15 \mathrm{~min}$ was enough to load a high amount of yeasts on apple pieces. In addition, the strains survived on the food system for at least 12 days. A second output of a two way ANOVA is the decomposition of a statistical hypothesis, which shows the quantitative effect of each categorical predictor. As an example, in Figure 1 there is a decomposition of the statistical hypothesis for S. cerevisiae var. boulardii. Immediately after immobilization, the viable count of the yeasts on apple pieces was 6.7-6.9 log cfu/g (Figure 1A) for all contact times (15-30 min), and it did not change throughout the storage of the biocatalysts at $4{ }^{\circ} \mathrm{C}$ for up to 12 days (Figure 1B).

Table 1. Statistical effects of the contact time of apple pieces in the mother solution (contact) and the duration of the storage at $4{ }^{\circ} \mathrm{C}$ on the viability of yeasts. One-way ANOVA and Tukey's test $(p<0.05)$. SS, sum of squares; df, degrees of freedom; MS, mean sum of squares.

\begin{tabular}{ccccc}
\hline Variables & SS & df & MS & $p$ \\
\hline Saccharomyces boulardii & & & & $>0.05$ \\
\hline Contact time & 2.315 & 3 & 0.772 & $>0.05$ \\
Storage & 3.456 & 5 & 0.038 & $>0.05$ \\
Contact x storage & 0.564 & 15 & & $>0.05$ \\
\hline W13 & & & 1.085 & $>0.05$ \\
\hline Contact time & 3.257 & 3 & 0.889 & $>0.05$ \\
Storage & 4.445 & 5 & 0.048 & $>0.05$ \\
Contact x storage & 0.721 & 15 & & $>0.05$ \\
\hline 17 & & & 1.523 & $>0.05$ \\
\hline Contact time & 4.568 & 3 & 0.691 & 0.062 \\
\hline
\end{tabular}
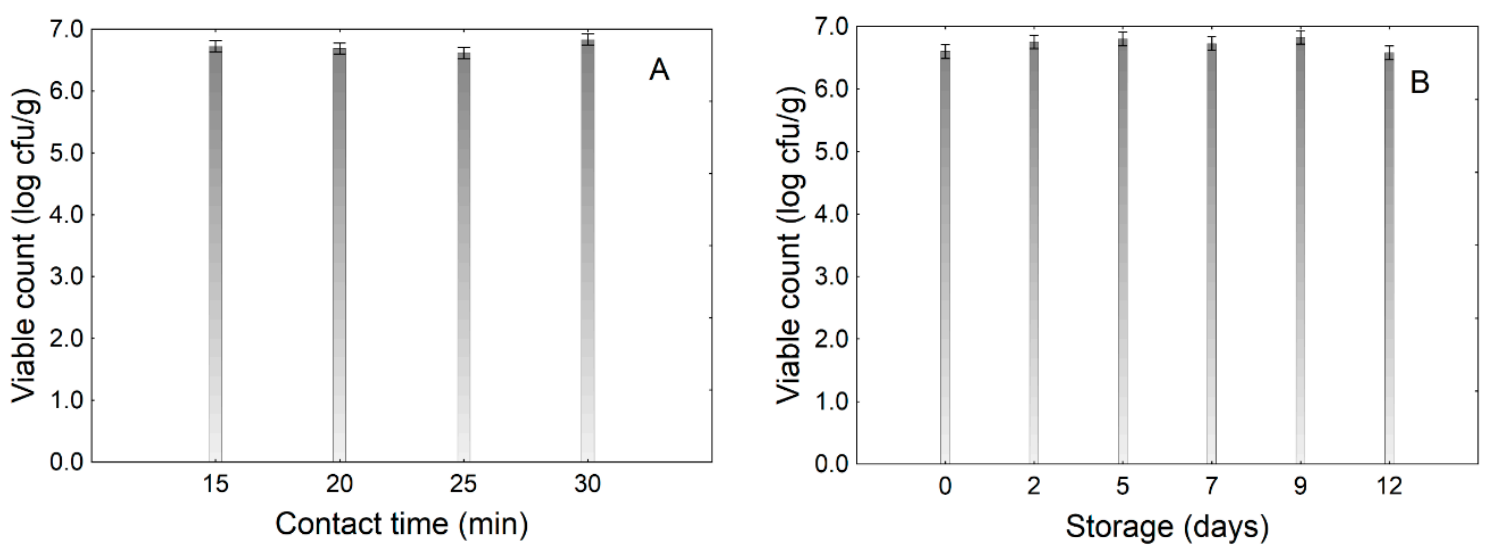

Figure 1. Decomposition of the statistical hypothesis for the effects of the contact time of the yeast solution/apple piece (A) and storage at $4{ }^{\circ} \mathrm{C}$ (B) on the viability of S. boulardii. Bars denote $95 \%$ confidence intervals. The differences were not significant (two-way ANOVA, $p>0.05$ ).

\subsection{Cider Production}

The goal of the second step was to study the possibility of using apple pieces as carriers for starter cultures for cider: S. cerevisiae W13 was used as a model strain. The yeast was loaded on apple pieces through a 15-min dipping. A second goal was to assess if it was possible to use the food-like systems after storage at $4{ }^{\circ} \mathrm{C}$ to simulate what a producer could do: to produce a biocatalyst and use it day-by-day. Therefore, two different experiments were performed: experiment A, with the biocatalyst being used immediately after yeast immobilization; and experiment $B$, where apple pieces were stored for 7 days and then used. 
For both experiments, another variable was studied: the possibility of reusing the biocatalysts.

The results of experiment A (pieces used immediately after their production) are in Figure 2. The viable count was reported as a function of the number of uses (Figure 2A), while in Figure 2B there was a yeast count in the cider after $24 \mathrm{~h}$ of fermentation.
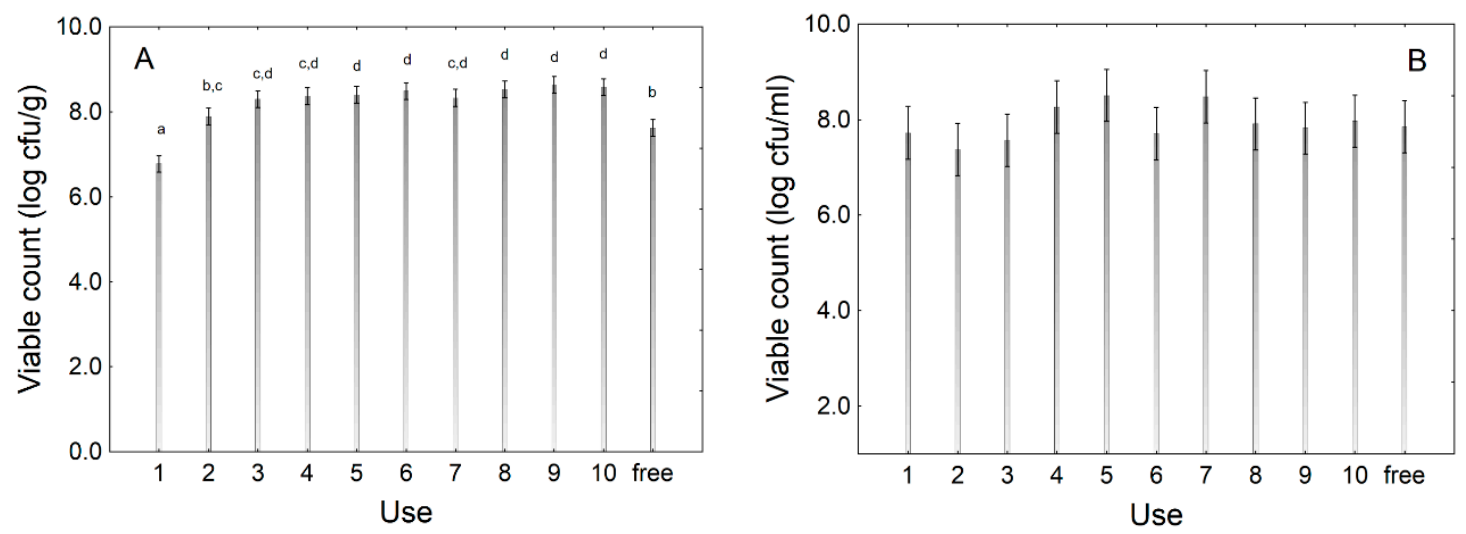

Figure 2. Viable count of S. cerevisiae W13 on apple pieces (experiment A) as a function of the number of uses (A) and after $24 \mathrm{~h}$ of fermentation in cider (B). Bars denote $95 \%$ confidence intervals. In (A), the letters indicate significant differences (one-way ANOVA and Tukey's test, $p<0.05$ ), while in (B), the samples were not significantly different $(p>0.05)$. Free, free cells (control).

The viable count of yeast on apple pieces after the first use was $6.78 \mathrm{log} \mathrm{cfu} / \mathrm{g}$. Then, it experienced a significant increase after the second $(7.88 \log \mathrm{cfu} / \mathrm{g})$ and third use $(8.28 \log \mathrm{cfu} / \mathrm{g})$. Concerning cider, the viable count after $24 \mathrm{~h}$ of fermentation was $7.5-8.0 \mathrm{log} \mathrm{cfu} / \mathrm{mL}$ without significant differences depending on the use of biocatalysts or the batch produced through free cells $(p>0.05)$. After the 10th use, apple pieces showed a reduced texture, and thus they were not used for further experiments (data not shown).

Figure 3 shows the results for experiment B (pieces stored at $4{ }^{\circ} \mathrm{C}$ before their use). As expected, the viable count of $S$. cerevisiae on apple pieces increased after the first use (from $6.72 \mathrm{log} \mathrm{cfu} / \mathrm{g}$ to $7.92 \log \mathrm{cfu} / \mathrm{g}$ ) (Figure 3A) $(p<0.05)$. In cider, the yeast was at 7.78-7.90 $\log \mathrm{cfu} / \mathrm{mL}$ without significant differences $(p>0.05)$ (Figure 3B), thus suggesting that a preliminary storage of apple pieces did not affect their performance as reusable biocatalysts.
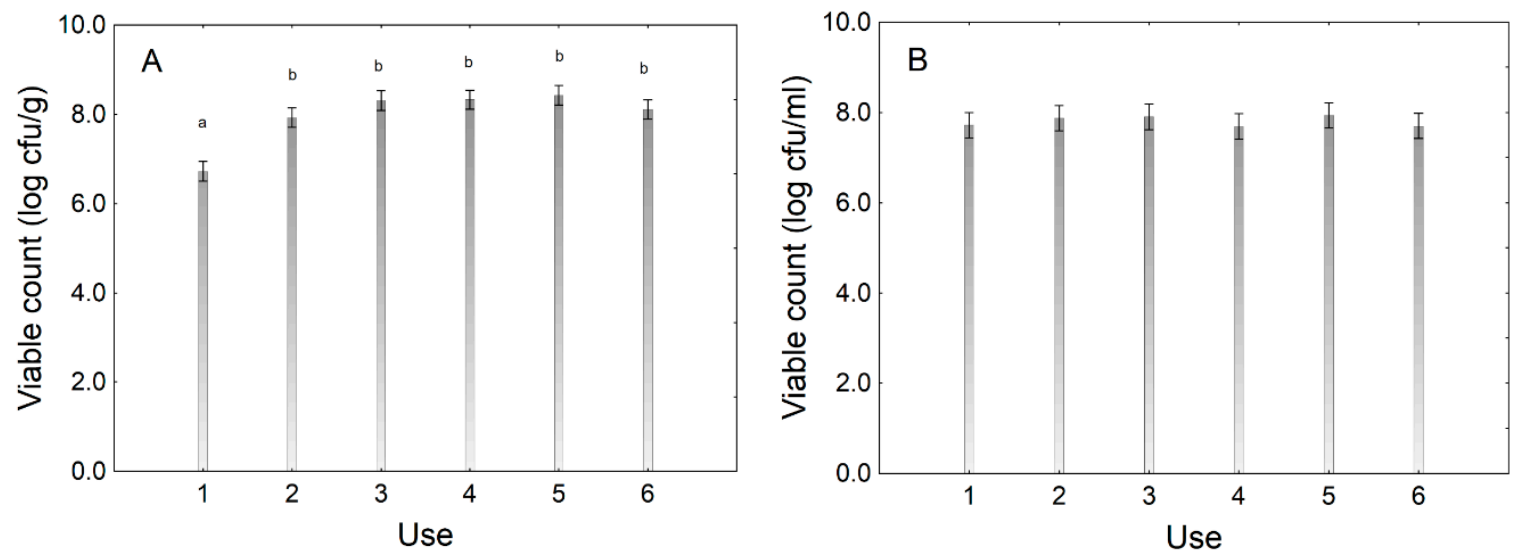

Figure 3. Results for experiment B (apple pieces stored at $4{ }^{\circ} \mathrm{C}$ for 7 days before their use). Viable count of S. cerevisiae W13 on apple pieces as a function of the number of uses (A) and after $24 \mathrm{~h}$ of fermentation in cider (B). Bars denote 95\% confidence intervals. In (A), letters indicate significant differences (one-way ANOVA and Tukey's test, $p<0.05$ ), while in $(\mathbf{B})$, the samples were not significantly different $(p>0.05)$. Free, free cells (control). 
After the sixth use, there was a significant loss in the texture of the apple pieces, and therefore their use as reusable biocatalysts was not advisable (data not shown).

The performance of the biocatalysts was also evaluated in terms of the ethanol produced after a 24-h fermentation: the results are in Table 2. Ethanol was from $2.23 \mathrm{~g} / \mathrm{L}$ (1st use) to $6.93 \mathrm{~g} / \mathrm{L}$ (10th use) for the cider produced with the biocatalysts and was at $3.10 \mathrm{~g} / \mathrm{L}$ for the cider fermented through free cells (experiment A). In experiment B, ethanol was from 3.09 (first use) to 2.03 (seventh use). The differences between the samples were not significant $(p>0.05)$.

Table 2. Ethanol (g/L) produced by S. cerevisiae W13 loaded on apple pieces after $24 \mathrm{~h}$ of fermentation. Mean values \pm standard deviation.

\begin{tabular}{ccc}
\hline Use & Experiment $\mathbf{A}_{\mathbf{1}}$ & Experiment B \\
\hline 1 & $2.23 \pm 1.08$ & $3.09 \pm 1.54$ \\
2 & $1.67 \pm 0.51$ & $4.75 \pm 0.44$ \\
3 & $2.39 \pm 0.58$ & $3.79 \pm 1.19$ \\
4 & $2.90 \pm 1.76$ & $3.52 \pm 1.67$ \\
5 & $2.92 \pm 1.52$ & $2.08 \pm 0.17$ \\
6 & $3.27 \pm 0.35$ & $2.03 \pm 0.21$ \\
7 & $2.28 \pm 0.50$ & - \\
8 & $2.25 \pm 0.32$ & - \\
9 & $5.17 \pm 2.72$ & - \\
10 & $6.93 \pm 3.52$ & - \\
Free & $3.10 \pm 0.14$ & - \\
\hline
\end{tabular}

${ }_{1}$ Experiment A: pieces used immediately after yeast immobilization. Experiment B: pieces stored for 7 days.

After fermentation, cider was assessed by a sensory panel: the results are in Figure 4 for odor and overall quality. The use of apple pieces as carriers for S. cerevisiae did not affect sensory perception, as the members of the panel did not find significant differences between the samples, and the sensory score for both odor and overall quality was 4 .

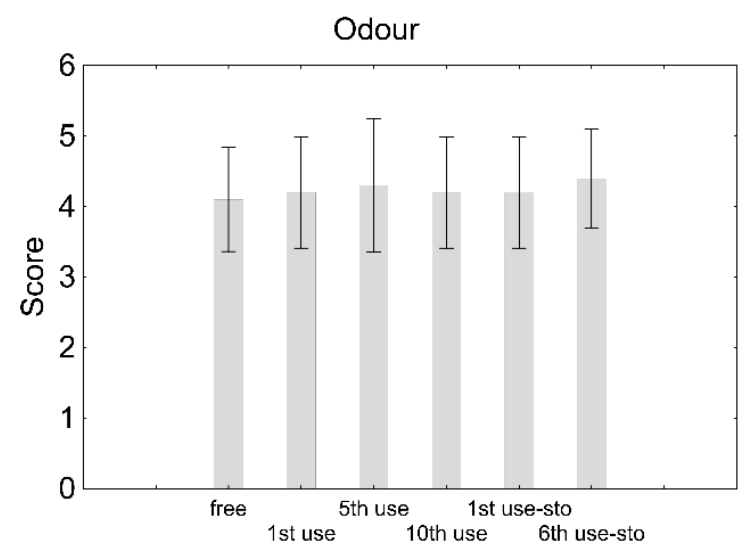

(A)

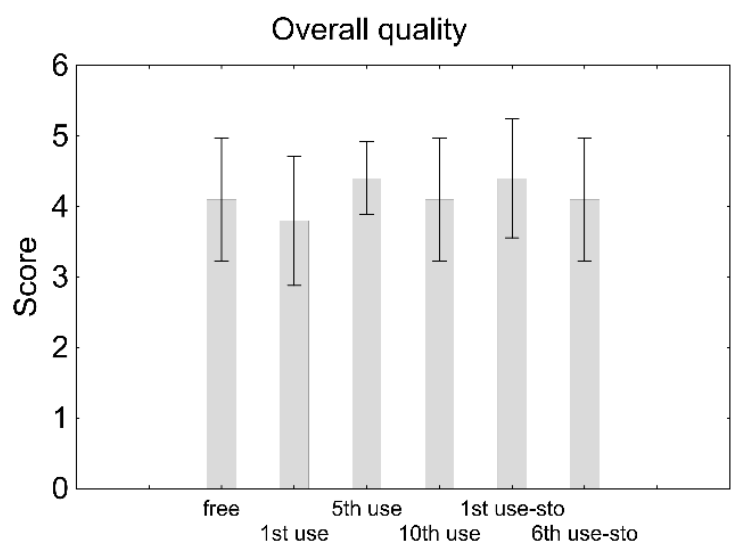

(B)

Figure 4. Results for the sensory scores (odor and overall acceptability) (mean \pm standard deviation). Free, cider produced with free $S$. cerevisiae; 1 st, 5th, and 10th use: cider from experiment A (A) with apple pieces used 1, 5, or 10 times; 1st use-sto and 6th use-sto: experiment B (B) (apple pieces stored at $4{ }^{\circ} \mathrm{C}$ for 7 days before their use) pieces used 1 or 6 times. The samples were not significantly different $(p>0.05$, Friedman test).

\section{Discussion}

Yeast immobilization offers many advantages for wine, beer, and cider production, such as a better control over yeasts, the possibility of designing reusable starter cultures, low costs, and customization of the process [5]. Nevertheless, the use of this technology in the production of fermented beverages is 
still limited [18] due to challenges such as the difficulty of maintaining cell viability over the process and, in the case of functional cells, also over the shelf life of the product $[19,20]$.

There are several main traits required for a carrier of starter cultures in wine-making $[5,21]$, including the following:

(a) Surface with functional properties, favoring yeast adhesion;

(b) Easy to handle and/or regenerate;

(c) High and retained cell viability and operational stability;

(d) Catalytic activity not affected;

(e) Cost-effective.

Kourkoutas et al. [22] highlighted the importance of consumer acceptance and safety issues, and thus they recommended supports that are abundant in nature, cost-effective, and of food-grade quality for successful industrial applications. This is the reason why apple pieces were used as carriers for yeasts to start apple juice fermentation: apples are abundant, the cost was low, and their effect on apple juice was expected to be not significant to quality. Moreover, a preliminary experiment showed that they are good carriers for S. cerevisiae [3].

Although several authors [5] have proposed yeast immobilization for wine production, this approach represents a novel way for cider. The main questions in the first step of this research were about the ability of yeasts to adhere on apple pieces, as the adhesion could be strongly strain-dependent, and on the duration of the process, as a long process could be interesting but expensive.

In terms of carrier optimization, the results of the first step showed that yeasts were able to survive for at least 12 days on apple pieces stored at $4{ }^{\circ} \mathrm{C}$. Moreover, they attained the highest cell load after $15 \mathrm{~min}$ of dipping in yeast solution. The optimal time for yeast immobilization (15 $\mathrm{min}$ ) was in agreement with the data of several researchers who studied yeast immobilization on a wide variety of supports (fruit pieces, nanofibrous membranes, oak chips) [3,23,24]. However, this novel result is based on the quantitative effect of the contact time: an increase of this parameter did not influence the performance of the immobilization system, and the possibility of using a contact time of $15 \mathrm{~min}$ is of great concern in terms of process management and apple piece handling.

In the second step, the issues addressed were the possibility of using the carriers several times and their performance after preliminary storage. The results suggested that carriers could be successfully used 10 times to ferment apple juice and produce cider. In addition, they experienced a comparable performance when preliminarily stored at $4{ }^{\circ} \mathrm{C}$. This result is of concern, as some authors have reported that yeast immobilization could result in some changes in yeast metabolism and affect the final products of their metabolism [5]. The data from experiment B suggest that S. cerevisiae W13 showed similar performances in terms of ethanol production independently of the number of uses of the carrier, the "age" of the carrier, or the duration of yeast immobilization before fermentation. This result could have strong practical implications because a producer could load yeasts on apple pieces and then store and use them when necessary, and this possibility greatly improves the management of this process.

This study is the first report on the possibility of producing cider by using yeasts immobilized on apple pieces: the carriers could be easily produced by a 15-min dipping of fruit pieces in yeast solution and could be used several times in 6 to 10 different fermentation processes. In addition, the pieces could be stored at $4{ }^{\circ} \mathrm{C}$ for several days before fermentation, thus suggesting that yeast immobilization and cider production could also be managed and performed at different times without affecting the catalytic activity of yeasts.

The performance of apple pieces, in terms of ethanol production, was similar to the conventional starter (free cells), and some preliminary sensory assays showed that the use of immobilized starters did not affect sensory traits. However, further assays are required to assess the performances of the carriers in larger volumes and under real conditions as well as to study their effect on the aromatic profile of cider. In conclusion, the main benefit of immobilized starters for cider production is probably based on saving time in the preparation of the starter cultures, as at an industrial level the preparation 
of a free starter requires $48-72 \mathrm{~h}$, and this procedure needs to be repeated every time (at least the last step of $24 \mathrm{~h}$ ). The design of a reusable starter could reduce this time, as it could act in the procedure for batch inoculation after the first preparation: pieces could be easily removed and used to start new fermentations in 30-60 min.

Author Contributions: Formal analysis, D.C. and A.B.; investigation, D.C. and B.S.; methodology, D.C.; project administration, M.R.C.; resources, M.R.C.; supervision, M.S. and A.B.; writing-original draft, C.A.; writing - review and editing, M.S., M.R.C., and A.B.

Funding: This research was funded by the University of Foggia, through the grant PRA 2017 (Progetti di Ricerca di Ateneo), the "use of biocompatible microbial immobilization systems for the production of food beverages" (Principal Investigator, Maria Rosaria Corbo).

Conflicts of Interest: The authors declare no conflicts of interest.

\section{References}

1. Kourkoutas, Y.; Bekatorou, A.; Banat, I.M.; Marchant, R.; Koutinas, A.A. Immobilization technologies and support materials suitable in alcohol beverages production: A review. Food Microbiol. 2004, 21, 377-397. [CrossRef]

2. Nedović, V.; Obradović, B.; Leskošek-Čukalović, I.; Trifunović, O.; Pešić, R.; Bugarski, B. Electrostatic generation of alginate microbeads loaded with brewing yeast. Process Biochem. 2001, 37, 17-22. [CrossRef]

3. Gallo, M.; Bevilacqua, A.; Speranza, B.; Sinigaglia, M.; Corbo, M.R. Alginate beads and apple pieces as carriers for Saccharomyces cerevisiae var. boulardii, as representative of yeast functional starter cultures. Int. J. Food Sci. Technol. 2014, 49, 2092-2100. [CrossRef]

4. Kourkoutas, Y.; Kanellaki, M.; Koutinas, A.A. Apple pieces as immobilization support of various microorganisms. LWT-Food Sci. Technol. 2006, 39, 980-986. [CrossRef]

5. Moreno-García, J.; García-Martinez, T.; Mauricio, J.C.; Moreno, J. Yeast immobilization systems for alcoholic wine fermentations: Actual trends and future perspectives. Front. Microbiol. 2018, 9, 241. [CrossRef]

6. Arevallo-Villena, M.; Briones-Perez, A.; Corbo, M.R.; Sinigaglia, M.; Bevilacqua, A. Biotechnological application of yeasts in food science. Starter cultures, probiotic, and enzyme production. J. Appl. Microbiol. 2017, 123, 1360-1372. [CrossRef] [PubMed]

7. Graff, S.; Hussain, S.; Chaumeil, J.C.; Charrueau, C. Increased intestinal delivery of viable Saccharomyces boulardii by encapsulation in microspheres. Pharm. Res. 2008, 25, 1290-1296. [CrossRef] [PubMed]

8. Ciccarelli, S.; Stolfi, I.; Caramia, G. Management strategies and treatment of neonatal and pediatric gastroenteritis. Infect. Drug Resist. 2013, 6, 133-161. [PubMed]

9. Serce, O.; Benzer, D.; Gursoy, T.; Karatekin, G.; Ovali, F. Efficacy of Saccharomyces boulardii on necrotizing enterocolitis or sepsis in very low birth weight: A randomized controlled trial. Early Hum. Dev. 2013, 89, 1033-1036. [CrossRef] [PubMed]

10. Shan, L.S.; Hou, P.; Wang, Z.J.; Liu, F.R.; Chen, N.; Shu, L.H.; Zhang, H.; Han, X.H.; Han, X.X.; Shang, Y.X.; et al. Prevention and treatment of diarrhea with Saccharomyces boulardii in children with acute lower respiratory tract infections. Benef. Microbes 2013, 4, 329-334. [CrossRef]

11. Bevilacqua, A.; Casanova, F.P.; Arace, E.; Augello, S.; Carfagna, R.; Cedola, A.; Delli Cari, S.; De Stefano, F.; Di Maggio, G.; Marinelli, V.; et al. A case-study on the selection of promising functional starter strains from grape yeasts: A report by student of Food Science and Technology degree, University of Foggia (Southern Italy). J. Food Res. 2012, 1, 44-54. [CrossRef]

12. Petruzzi, L.; Bevilacqua, A.; Baiano, A.; Beneduce, L.; Corbo, M.R.; Sinigaglia, M. Study of Saccharomyces cerevisiae W13 as a functional starter for the removal of ochratoxin A. Food Control 2014, 35, 373-377. [CrossRef]

13. Petruzzi, L.; Bevilacqua, A.; Corbo, M.R.; Garofalo, C.; Baiano, A.; Sinigaglia, M. Selection of authochtonous Saccharomyces cerevisiae as strains as wine starters using a polyphasic approach and ochratoxin A removal. J. Food Prot. 2014, 77, 1168-1177. [CrossRef] [PubMed]

14. Rosend, J.; Kuldjärv, R.; Rosenvald, S.; Paalme, T. The effects of apple variety, ripening stage, and yeast strain on the volatile composition of apple cider. Heliyon 2019, 5, 201953. [CrossRef]

15. Laaksonen, O.; Kuldjärv, R.; Paalme, T.; Virkki, M.; Yang, B. Impact of apple cultivar, ripening stage, fermentation type and yeast strain on phenolic composition of apple ciders. Food Chem. 2017, 233, $29-37$. [CrossRef] [PubMed] 
16. Perricone, M.; Bevilacqua, A.; Corbo, M.R.; Sinigaglia, M. Technological characterization and probiotic traits of yeasts isolated from Altamura sourdough to select promising microorganisms as functional starter cultures for cereal-based products. Food Microbiol. 2014, 38, 26-35. [CrossRef]

17. Kopsahelis, N.; Panas, P.; Kourkoutas, Y.; Koutinas, A.A. Evaluation of the thermally dried immobilized cells of Lactobacillus delbrueckii subsp. bulgaricus on apple pieces as a potent starter culture. J. Agric. Food Chem. 2007, 55, 9829-9836. [CrossRef]

18. Berbegal, C.; Spano, G.; Tristezza, M.; Griego, F.; Capozzi, V. Microbial resources and innovation in the wine production sector. S. Afr. J. Enol. Viticult. 2017, 38, 156-166. [CrossRef]

19. Weinbreck, F.; Bodnar, I.R.; Marco, M.L. Can encapsulation lengthen the shelf-life of probiotic bacteria in dry products? Int. J. Food Microbiol. 2010, 136, 364-367. [CrossRef]

20. Corbo, M.R.; Bevilacqua, A.; Gallo, M.; Speranza, B.; Sinigaglia, M. Immobilization and microencapsulation of Lactobacillus plantarum: Performances and in vivo applications. Innov. Food Sci. Emerg. Technol. 2013, 18, 196-201. [CrossRef]

21. Nedović, V.; Gibson, B.; Mantzouridou, T.F.; Bugarski, B.; Djordjević, V.; Kalušević, A.; Paraskevopoulou, A.; Sandell, M.; Šmogrovičová, D.; Yilmaztekin, M. Aroma formation by immobilized yeast cells in fermentation processes. Yeast 2015, 32, 173-216. [CrossRef] [PubMed]

22. Kourkoutas, Y.; Mc Erlean, C.; Kanellaki, M.; Hack, C.J.; Marchant, R.; Banat, I.M.; Koutinas, A.A. High-temperature wine making using the thermotolerant yeast strain Kluyveromyces marxianus IMB3. Appl. Biochem. Biotechnol. 2004, 112, 25-35. [CrossRef]

23. Berbegal, C.; Polo, L.; García-Esparza, M.J.; Lizama, V.; Ferrer, S.; Pardo, I. Immobilisation of yeasts on oak chips for use in bottle-fermented sparkling wine. Food Microbiol. 2019, 78, 25-37. [CrossRef] [PubMed]

24. Armani, M.; Morozova, K.; Scampicchio, M. Immobolization of Saccharomyces cerevisiae on nylon-6-nonofibrous membranes for grape juice fermentation. LWT-Food Sci. Technol. 2019, 110, 360-364. [CrossRef]

(C) 2019 by the authors. Licensee MDPI, Basel, Switzerland. This article is an open access article distributed under the terms and conditions of the Creative Commons Attribution (CC BY) license (http://creativecommons.org/licenses/by/4.0/). 